
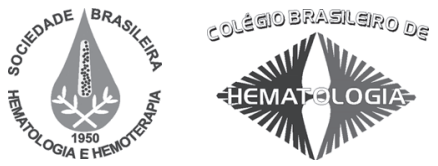

Revisão / Review

\title{
Células-tronco de medula óssea em isquemia crítica de membros
}

\section{Bone marrow stem cells in critical limb ischemia}

\author{
José Dalmo Araujo \\ José Dalmo Araujo Filho ${ }^{2}$ \\ Emerson Ciorlin ${ }^{3}$ \\ Milton A. Ruiz ${ }^{4}$ \\ Oswaldo T. Greco 5 \\ Roberto V. Ardito ${ }^{6}$ \\ Mario $\operatorname{Lago}^{7}$
}

\begin{abstract}
Os autores discutem aspectos clinicos e de tratamento convencional da isquemia critica dos membros inferiores e consideram a possibilidade de tratamento com células-tronco autógenas de medula óssea para os pacientes que já esgotaram, sem sucesso, todos os meios de tratamento conhecidos. Comentam sobre o histórico, as fontes, as experiências animais e clínicas e, finalmente, apresentam sua experiência inicial com seis pacientes, todos com indicação de amputação maior ou menor. Em apenas um paciente não foi possível evitar a amputação. Além de ótimos resultados, quanto à supressão da dor e cicatrização de lesões isquêmicas, pode-se notar a ausência de quaisquer efeitos colaterais deletérios, sugerindo que a terapia celular é eficiente e segura, demandando, porém, mais pesquisas e estudos randomizados para se tornar uma terapia de uso corrente. Rev. Bras. Hematol. Hemoter. 2009;31(Supl. 1):128-139.
\end{abstract}

Palavras-chave: Células-tronco; isquemia crítica; células-tronco adultas; medula óssea.

\section{Introdução}

A isquemia crítica dos membros inferiores (ICMI) secundária a obstrução arterial crônica, não compensada por circulação colateral adequada, manifesta-se por dor isquêmica, em repouso e/ou úlcera isquêmica ou gangrena. Os portadores apresentam Índice Tornozelo/Braço inferior a 0,5. Este índice é calculado dividindo-se a pressão arterial medida no tornozelo por aquela do braço. O valor normal é igual ou maior que 1 e a sensibilidade para diagnóstico de doença arterial obstrutiva periférica (DAOP) chega a $99 \%{ }^{1,2}$

Pacientes com ICMI devem ser tratados através de revascularização com enxertos autógenos (veias safenas, artérias radiais e outros). Enxertos sintéticos são alternativas de exceção. ${ }^{3,4}$ As técnicas usadas são as derivações em pon- te (bypass), ou endarterectomias com ou sem remendo (patch). ${ }^{5}$ As técnicas endovasculares com colocação de stents estão em franco desenvolvimento e são usadas com frequência crescente. ${ }^{6}$

É grande a incidência de amputações por ICMI. Cerca de 4 mil por 1 milhão de pessoas/ano sofrerão amputações de grande porte. ${ }^{3}$ No Brasil, seriam aproximadamente 860 mil pessoas/ano.

Além disso, pacientes com ICMI têm expectativa de vida $25 \%$ menor $^{3}$ e, após grandes amputações, $50 \%{ }^{7,8} \mathrm{~A}$ causa de morte é, principalmente, o infarto do miocárdio. Há situações em que não se consegue a revascularização: falta de enxerto autógeno, falta de deságue (run-off) para o enxerto ou, mesmo, falhas técnicas.

A terapia farmacológica, incluindo prostaglandinas,

${ }^{I}$ Cirurgião vascular. Chefe do Serviço de Cirurgia Vascular do IMC - São José do Rio Preto-SP.

${ }^{2}$ Cirurgião Vascular e Endovascular do IMC de São José do Rio Preto-SP.

${ }^{3}$ Cirurgião Vascular e Angiologista do IMC de São José do Rio Preto-SP.

${ }^{4}$ Professor colaborador da Disciplina de Hematologia e Hemoterapia da FMUSP-SP e coordenador do Grupo de Terapia Celular

do IMC/HMC - São José do Rio Preto-SP

${ }^{5}$ Cardiologista e Diretor Cientifico do IMC, editor Relampa/Deca/SBCCV/SBC, presidente da Faperp.

${ }^{6}$ Cirurgião cardíaco. Chefe do Serviço de Cirurgia Cardíaca do IMC.

${ }^{7}$ Biomédico do IMC - São José do Rio Preto-SP.

Instituto de Moléstias Cardiovasculares de São José do Rio Preto (IMC)-SP.

Correspondência: José Dalmo de Araujo

Rua Castelo D'Água, 3030 - Bairro Redentora

15015210 - São José do Rio Preto-SP - Brasil

E-mail:jdalmo@terra.com.br

Doi: $10.1590 /$ S1516-84842009005000031 
vasodilatadores e outros, mostra resultados pobres. ${ }^{9,10}$

A terapia celular com células-tronco adultas (CTA) surge como alternativa para esses casos, nos quais já se esgotaram todos os métodos de tratamento conhecidos.

O fato de não terem os problemas de ordem ética das células embrionárias, de serem coletadas com relativa facilidade e em número satisfatório, prescindindo da cultura e seus problemas, tem feito as CTA gozarem de certa preferência nos ensaios clínicos em andamento. Por outro lado, são células embriologicamente mais evoluídas e, por isso, com menor risco de desvios ontogênicos e efeitos colaterais.

\section{Células-tronco adultas}

São células indiferenciadas que podem se renovar e reproduzir indefinidamente e, sob certos estímulos, se transformar em células especializadas de diferentes tecidos ou órgãos. Isso se faz através da divisão assimétrica, originando uma célula comprometida com a diferenciação e outra que mantém as características primitivas da célula original, repondo o número de células indiferenciadas.

Baseados neste conceito, os pesquisadores começaram a considerar a possibilidade do seu transplante para recompor tecidos destruídos por doenças, por traumas ou por terapias agressivas. De fato, o transplante de células de medula óssea tem sido feito há mais de 40 anos para recompor medulas destruídas por quimioterapia ou radiação e, dessa forma, repor as células sanguíneas, por exemplo, nas leucemias e linfomas. (Figura 1)

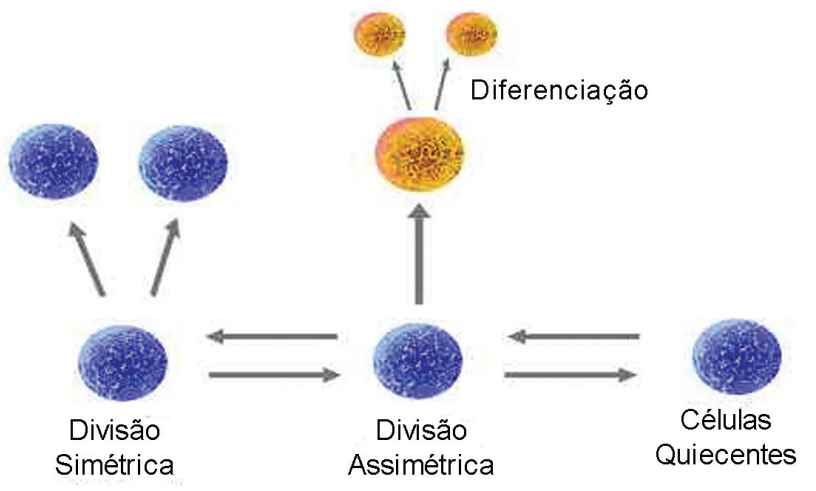

Figura 1

\section{Histórico}

O primeiro transplante de CTA em humanos foi feito por Thomas em 1957 em gêmeos univitelinos, para tratamento de leucemia. ${ }^{11}$

$\mathrm{Na}$ década de 60, pesquisadores descobriram que a medula óssea contém, pelo menos, dois tipos de células-tronco: as hematopoéticas, que formam todos os tipos de células sanguíneas e endoteliais, e as células do estroma, uma população mista que pode gerar osso, cartilagem, gordura e tecido fibroso e conjuntivo.

As CTA são encontradas no fígado, ${ }^{12}$ cérebro $^{13}$ tecido gorduroso ${ }^{14}$ e medula óssea. ${ }^{15,16}$ Esta última é a que apresenta quantidade maior de células. Nos outros tecidos, as células existem em pequena quantidade. Trabalha-se, por isto, no desenvolvimento de técnicas de cultura que propiciem o número de células adequado para terapia. Este número, em geral, chega à casa dos bilhões. ${ }^{17,18}$

Supõe-se que as CTA permaneçam quiescentes (sem se dividirem) nos tecidos que constituem seu habitat, até que sejam ativadas por doenças, inclusive tumores, ou trauma e, também, para fazer a reposição de células "gastas" no organismo ao longo da vida, através da liberação, no sangue circulante, de células progenitoras (CP) que seriam mobilizadas para os locais onde se fizessem necessárias. Esta mobilização seria feita por substâncias liberadas no local da lesão. ${ }^{19}$ Seria, assim, uma espécie de "departamento de manutenção" que, com a idade, vai diminuindo sua intensidade de atuação. De fato, há trabalhos mostrando que as $\mathrm{CP}$ circulantes diminuem com a idade. ${ }^{20,21,22}$

As CP agem na reparação de traumas do endotélio, promovendo sua remodelação de forma a evitar a hiperplasia fibromuscular, ${ }^{23,24,25}$ embora alguns trabalhos sugiram que elas tenham participação na sua formação, quando não há uma modulação adequada de sua ação. ${ }^{26}$ Foi relatada a ação benéfica das CP no equilíbrio do metabolismo lipídico ${ }^{27}$ e observou-se o aumento do seu número com a atividade física ${ }^{28}$ e o uso de estatinas. ${ }^{29,30}$ Por outro lado, o número de CP diminui com o aumento dos fatores de risco ${ }^{31}$ principalmente com o diabete ${ }^{32}$ e com doença isquêmica crônica instalada. ${ }^{33}$

Quando a CTA, não diferenciada, se transforma na célula do tecido onde ela "reside", diz-se que houve uma diferenciação. Quando a CTA se transforma em tecido de outro órgão, que não o seu, diz-se que houve uma transdiferenciação.

Com respeito ao desenvolvimento das células sanguíneas e endoteliais, parece que ambas têm o mesmo precursor: o hemangioblasto, que aparece precocemente no embrião e, rapidamente, desaparece, após o nascimento. ${ }^{34}$ Ontogenicamente, o hemangioblasto está ligado no VEGFR2 (Vascular endothelial growth factor receptor-2). ${ }^{35}$ Ratos que não têm o VEGFR-2 apresentam um desvio patológico tanto nas células hematopoéticas quanto na vasculatura. ${ }^{36,37}$

Por outro lado, células VEGFR-2 positivas isoladas de embriões geraram colônias mistas hematopoéticoendoteliais quando em cultura unicelular. ${ }^{38}$ Estudos adicionais mostraram que, após o nascimento, células que têm os marcadores de superfície CD 133, CD 34 e VGFR-2 formam um subconjunto de células na medula óssea, sangue periférico e sangue do cordão umbilical que possuem atividade funcional de hemangioblastos, pois são capazes de se diferenciarem tanto em células endoteliais quanto hematopoéticas. ${ }^{39}$ São 25 células endoteliais progenitoras (CEP). 
Assahara $e t a l^{40}$ foram os primeiros a descrever sua existência na medula óssea e a sua participação na formação de novos vasos em adultos. Já na década de 60 , células endoteliais circulantes (CE), derivadas das CEP, foram demonstradas em tubos de Dacron implantados em aortas de porcos, coelho e cão. ${ }^{41}$ Da mesma forma, CE foram demonstradas em dispositivos de assistência ventricular (coração artificial). ${ }^{42}$

As CEP podem formar novos vasos por três mecanismos; a) angiogênese - capilares que resultariam de brotos originados de vasos já existentes ${ }^{43}$ b) arteriogênese - aparecimento de vasos que estariam "adormecidos", embora alguns acreditem na possibilidade de neoformação, ${ }^{44} \mathrm{c}$ ) vasculogênese - formação de novos vasos ou remodelação dos já existentes. ${ }^{45}$

Parece que a arteriogênese é o mecanismo mais eficiente para aumento da circulação (vinte a trinta vezes), enquanto a angiogênese aumenta (duas a três vezes), e a vasculogênese ainda não foi adequadamente dimensionada. ${ }^{45}$

Estímulos especiais mobilizariam as CEP que poderiam produzir simultaneamente a angiogênese e a vasculogênese, imitando o processo embrionário. A arteriogênese (circulação colateral) seria produzida pelas variações no trauma de atrito (shear stress), que liberariam substâncias mobilizadoras do endotélio e ativariam CEP circulantes. ${ }^{44}$

Os estímulos para a mobilização das CTA são gerados por substâncias liberadas na zona isquêmica (milieu dependent) como o fator de crescimento endotelial - VEGF (Vascular endothelial growth factor), fator de crescimento dos fibroblastos - FGF (Fibroblast growth factor), citocinas, quimiocinas angiopoietinas e outros. ${ }^{46}$

Outra possibilidade é a de que as próprias CTA produziriam esses fatores de estímulo que concorreriam para a formação de novos vasos, inclusive estimulando células progenitoras "residentes" na região isquêmica (atividade parÁcrina), concorreriam para a melhora do funcionamento do endotélio dos vasos remanescentes e, ainda, promoveriam sua vasodilatação. ${ }^{47,48}$ É provável que haja uma associação desses vários mecanismos para que haja vasculogênese.

Recentemente, Dong et al. ${ }^{49}$ demonstraram, em ratos, que as células-tronco da medula óssea (CTMO) têm a capacidade para produzir óxido nítrico (NO), participando, através de efeitos parácrinos, na infiltração dessas células através da parede vascular. As CTMO poderiam influenciar no diâmetro e na permeabilidade vascular para invadir o tecido isquêmico. A terapia celular com CTMO induziria a vasodilatação, levando a um aumento de fluxo para o tecido isquêmico melhorando a sua perfusão. Na nossa observação, é o efeito mais notado, logo nos primeiros dias após o implante, com melhora de cor e temperatura e diminuição da dor isquêmica.

As mudanças na permeabilidade vascular resultam na deposição de gel de fibrina extravascular, fornecendo matriz para a neoangiogênese. ${ }^{50}$
A liberação do gene da sintetase do óxido nítrico endotelial (eNOS) promove a revascularização pós-isquemia, sugerindo que o óxido nítrico liberado pela CTMO deve disparar numerosos sinais para o crescimento de vasos sanguíneos. ${ }^{51}$

A ativação de eNOS nas CTMO ou nas células endoteliais progenitoras (CEP) constitui um caminho para melhorar a terapia celular em patologias que levam à disfunção das CEP e eNOS,${ }^{52}$ como nos diabéticos.

O que, porém, parece bem definido é que os fatores de crescimento, as citocinas, quimiocinas, angiopoietinas e outros são imprescindíveis em todo o processo e estariam todos englobados no sistema HIF (Hypoxia inducible factor), tendo, cada um deles, diferentes variantes tanto na sua parte ativa quanto nos seus receptores. ${ }^{45}$

Aliás, é nesse conceito que se baseia a terapia gênica, que consiste na administração desses fatores por meio de vetores virais ou, então, plasmídeos. É de se esperar, para maior eficiência, a associação das terapias gênica e celular. Na verdade já há trabalhos reportando esta associação. ${ }^{53,54,55}$ Alguns deles sugerem, inclusive, a associação de dois fatores de crescimento, p.ex. VEGF, que formaria tubos endoteliais muito permeáveis, e FGF, que promoveria a formação das partes fibrosa e muscular. ${ }^{56}$

O problema de a terapia gênica ser mais complexa e laboriosa, envolvendo riscos potenciais quando os vetores são virais, bem como reações adversas a substâncias químicas usadas no seu preparo e, ainda, de os fatores de crescimento terem vida média muito curta, será, certamente, resolvido. É esperado também que as próprias células-tronco recebam marcações genéticas novas que ajudarão a tratar as doenças, inclusive transportando fatores de crescimento específicos para órgãos determinados ${ }^{57}$ Em revisão recente, Araújo e colaboradores analisam a literatura sobre o assunto. ${ }^{58}$

\section{Marcadores das células endoteliais progenitoras}

As CEP são identificadas, basicamente, de duas maneiras: pela determinação, através de anticorpos monoclonais específicos, de marcadores de superfície como o CD $34^{+}($Cell diferentiation), CD 133 ${ }^{+}$, VEGF e outros, ${ }^{59}$ que dão as características fenotípicas das células e, também, através de técnicas que utilizam as reações em cadeia de polimerase (PCR Polimerase chain reaction) e, principalmente, a RT-PCR (Reverse transduction - PCR) através das quais se identificam as células pelo seu DNA. ${ }^{45}$

Importante, também, é lembrar que as CEP podem ter mais do que uma expressão genética de superfície: FVW (Fator de Von Willebrand), CD 45, CD 14, E-selectine, CD133 e outros. ${ }^{45,59}$ Também, alguns marcadores de superfície, como o CD $133^{+}$, deixam de se expressar, após a transformação em células endoteliais, transformando-se em CD133- (CD 133 negativo) ${ }^{60}$ 
A importância dos marcadores é que eles permitem separar as células e acompanhá-las, observando sua localização nos tecidos (homing) e, eventualmente, os diferentes tempos até sua diferenciação.

\section{Experimentação animal com células-tronco na isquemia periférica}

Os resultados das experiências com células-tronco em patologias do miocárdio, doenças imunológicas, doenças e traumas neurológicos, diabete e outras são frequentemente entusiasmantes em animais, mas nem sempre se confirmam em humanos, nos quais as informações de sucesso variam de nulas a excelentes. ${ }^{45}$ Vamos nos limitar a rever as publicações sobre isquemia periférica.

Iba et $a l .{ }^{46}$ mostraram, em animais, que a injeção de células mononucleares humanas circulantes melhorava a densidade capilar em modelos de membros isquêmicos de ratos atímicos, através de fatores angiogênicos, principalmente o VEGF e citocinas, e que anticorpos anti-VEGF inibiam a formação de novos vasos, assim como a associação de polimorfonucleares ao extrato de células.

É importante, neste trabalho, a observação de que a injeção de polimorfonucleares associada diminuia a ação dos extratos de células mononucleares associadas a plaquetas do sangue periférico humano, quanto ao aumento da perfusão sanguínea. $\mathrm{O}$ mesmo acontecia quando se fazia incubação prévia com anti-VEGF. Em um lote de pacientes, o sangue da medula óssea continha cem vezes mais células $\mathrm{CD} 34^{+}$do que o sangue periférico. Há autores que afirmam quinhentas vezes. ${ }^{61}$ As células $\mathrm{CD} 34^{+}$são potencialmente CEP $(18 \%)$.

Quando o mesmo número de células mononucleares eram injetadas ( $10^{7}$ células), o efeito angiogênico das células do sangue periférico corresponderia a cerca de $70 \%$ do efeito das células mononucleares da medula óssea (fato confirmado por Yuyama ${ }^{61}$.

Um outro dado importante: o trabalho mostra que o efeito angiogênico e a incorporação de células $\mathrm{CD} 34^{+}$nos capilares neoformados são número-dependentes (é necessário um mínimo de $10^{5}$ células $\mathrm{CD} 34^{+}$). Isto explica o esforço dos pesquisadores em injetar, em pacientes, número de células mononucleares acima de $10^{8}$.

Em resumo, os polimorfonucleares diminuem e 0 antiVEGF abole a ação angiogênica das células mononucleares associadas a plaquetas do sangue periférico; as células mononucleares têm efeito angiogênico maior, e este efeito parece ser número de células dependente.

Al-khaldi et al. ${ }^{62}$ demonstraram, em ratos, que a injeção de células do estroma da medula óssea humana em membros isquêmicos produzia neovasculogênese com aumento do fluxo sanguíneo e regeneração dos vários componentes musculares.

Neste trabalho foram usadas células do estroma da medula, que são pluripotentes. Entretanto, devido ao seu pequeno número, estas células tiveram que ser cultivadas. Inicialmente, cultivou-se o sangue da medula por sete dias e, depois, descartaram-se as células hematopoéticas não aderentes a um tipo de placa usada no processo de separação. As células aderentes eram do estroma. Elas foram marcadas e cultivadas por mais três dias e, então, dissolvidas em albumina bovina a $20 \%$, em salina, e injetadas no compartimento muscular ântero-medial do modelo de membro isquêmico. Houve aumento do número de vasos e do fluxo sanguíneo.

A cultura de células do estroma medular é desejável devido ao fato de serem comprovadamente pluripotentes (mais do que as células mononucleares). Entretanto, necessita em torno de dez dias para ser realizada. Além disso, as células do estroma têm uma facilidade maior de mutação genética que torna necessário um controle maior, para evitar neoangiogênese patológica e formação de tumores. É desejável que essa cultura seja aprimorada, mas, no momento, o uso das células mononucleares autógenas da medula se mostra mais prático e mais seguro.

Li et al..$^{63}$ injetaram células de medula óssea pré-estimuladas por hipóxia ex vivo e notaram que a expressão de VEGF e de diferenciação endotelial eram maiores do que as células processadas em normoxia. Vê-se, neste trabalho, que os autores partem do princípio de que a ação angiogênica das células mononucleares da medula óssea é um fato definitivamente comprovado.

Os resultados melhorados com pré-estímulos por hipóxia, entretanto, exigem cultura e, para serem considerados como definitivos, necessitam ser repetidos por outros autores. Não estamos seguros de que o custo/benefício seja favorável.

Também, trabalho mais recente mostra que a estimulação das $\mathrm{CEP}$ com $\mathrm{H}_{2} \mathrm{O}_{2}$ produzia maior efeito angiogênico das CEP através do aumento da expressão do VEGF. ${ }^{64}$ Portanto, ao contrário da hipóxia, a hiperóxia seria o estímulo. Os autores sugerem que este poderia, inclusive, ser um método alternativo às técnicas de modificação genética, de difícil implementação.

Por outro lado, trabalhos recentes ${ }^{65,66}$ mostram que a oxigenioterapia hiperbárica libera CEP da medula óssea em pacientes diabéticos e/ou com isquemia crônica. Estas CEP são funcionalmente efetivas. Ocorre também um aumento nítido de células com epítopo CD $34^{+}$, que são da linha dos hemangioblastos, que dão origem a células hematopoéticas e endoteliais.

A liberação das CEP da medula também ocorre por estímulo de citocinas, quimiocinas, fatores de crescimento (VEGF) que ativam a óxido nítrico sintetase (ONS) no estroma medular que, por ação parácrina, gera o óxido nítrico $(\mathrm{ON})$, que ativa a metaloproteinase da matriz MMP-9 (Matrix metaloproteinase-9), que libera a citocina Kit ligand que libera as CEP. Estas CEP são dirigidas para as zonas isquêmicas por mediação da SDF-1x (componente do HIF - Hypoxia inducible 
factor). O receptor dos CEP é a quimiocina CXCRY, da família CXC. ${ }^{67}$

Baseados no conhecimento de que as células mesenquimais da medula podem secretar citocinas e outros fatores de crescimento, Shintani et al. ${ }^{68}$ mostraram, em animais, que a implantação de células mononucleares de medula óssea, em membros isquêmicos, também promove formação de novos vasos, com incorporação de CEP em capilares, e que a concentração de FGF, VEGF e citocinas aumentava nos tecidos do membro implantado.

Este trabalho foi o estudo pré-clínico de Yuyama ${ }^{61} \mathrm{com}$ 47 pacientes, citado adiante. É importante a confirmação de que as CEPs realmente podem advir das células mononucleares da medula óssea, mostrando a origem comum com as células hematopoéticas já comentadas atrás.

Iwaguro et al. ${ }^{57}$ mostraram em ratos atímicos que a injeção de CEP heterólogas marcadas com VEGF aumentava a circulação mais do que em animais controle (injeção de CEP sem VEGF). Seria um caso de associação de terapia gênica e celular. O VEGF é incorporado às CEP do sangue periférico por meio de adenovírus e os autores dizem que, com isto, a dose de CEP necessária era trinta vezes menor. Se visarmos o objetivo prático de administração em humanos, a utilização de CEP do sangue da medula óssea é mais racional, pois este sangue contém cem a quinhentas vezes mais células $\mathrm{CD} 34^{+}$que o sangue periférico. ${ }^{46,61} \mathrm{Um}$ outro óbice diz respeito à vida média muito curta do VEGF e à possibilidade de reações imunológicas ao adenovírus, do tempo necessário para cultura e transferência genética e de possíveis reações às substâncias químicas utilizadas em todo o processo.

Silvestre et al.$^{69}$ demonstraram, em ratos, a importância da interleucina-10, um agente anti-inflamatório, na neovasculogênese. A presença de inflamação (ratos interleucina negativos) favorecia a angiogênese enquanto a diminuição da inflamação (ratos interleucina positivos) diminuía a angiogênese pela regulação, para baixo, do VEGF. A presença de inflamação, portanto, seria um fator positivo para a neovasculogênese.

Estes dados poderão ter utilidade prática no sentido de não se utilizarem anti-inflamatórios quando do tratamento de isquemia crítica com terapia celular ou gênica.

Colledge et al. ${ }^{67}$ sugerem uma associação entre doença óssea e doença arterial, tendo as CEPs como protagonistas e resumem sua ação em três fases: mobilização, recrutamento e diferenciação. Destacam que, ainda, há muito o que aprender, particularmente sobre a fase de diferenciação, inclusive, se existe a possibilidade de desdiferenciação.

\section{Experiências clínicas com células-tronco adultas}

Como sequência do trabalho de Shintani, ${ }^{68}$ Yuyama et al. ${ }^{61}$ publicaram, em 2002, sua experiência clínica, com 47 pacientes nos quais fizeram randomização (não duplo-cega).
Os pacientes eram divididos em dois grupos: 25 apresentavam isquemia crítica unilateral (grupo A) e 22, bilateral (grupo B). No grupo A foram injetadas células mononucleares da medula óssea na perna com isquemia crítica e soro fisiológico na perna contralateral. No grupo B foram injetadas células mononucleares da medula óssea em uma das pernas e células mononucleares do sangue periférico na outra.

Observou-se diminuição da dor na maioria dos pacientes de ambos os grupos injetados com células mononucleares da medula óssea; estes pacientes também mostraram melhora significativa do índice tornozelo/braço, da pressão transcutânea de oxigênio e, aos seis meses, a angiografia mostrou melhora notável na circulação colateral em 27 dos 47 pacientes (15 no grupo A e 12 no grupo B). Em um paciente que morreu de infarto do miocárdio três meses após o implante, o estudo histológico de fragmentos do gastrocnêmico revelou aumento grande da vascularização (relação músculo/capilares), quando comparado com o membro em que se injetou salina. A dor desapareceu em 22 pacientes (12 no grupo A e dez no grupo B) e houve melhora da dor em repouso em 15 pacientes (nove no grupo A e seis no grupo B). A amputação de dedos foi evitada em 15 de vinte pacientes (oito no grupo A e sete no grupo B). Houve melhora de úlceras isquêmicas em seis de dez pacientes (três em cada grupo). O grupo de pernas injetado com células mononucleares do sangue periférico mostrou resultados menos significativos.

Este trabalho é muito importante, pois foi o primeiro a ter randomização. Além disso, mostrou que não houve nenhum efeito adverso (local ou sistêmico), em até dois anos de seguimento, apesar de um aumento transitório da CPK.

Nos membros implantados com células mononucleares da medula foi observado, nas biópsias musculares, que células CD $31^{+}$endoteliais expressavam Ki-67, proteína nuclear que expressa atividade proliferativa, enquanto nas pernas injetadas com salina não havia expressão de Ki-67. Isto sugere que as injeções intramusculares, por si só, não desencadeariam atividade proliferativa e, portanto, não desencadeariam angiogênese. Também não se notou, nas peças de biópsias, a formação de osteoblastos, fibrose anormal ou acúmulo de células inflamatórias.

Outra observação importante: o tratamento prévio com GCSF (Granulocyte-colony stimulating factor) pode aumentar o número de CEP na medula e sangue periférico, mas, segundo os autores, não foi usado neste trabalho porque provoca leucocitose e hipercoagulabilidade. Além disso, é muito grande o número de trabalhos experimentais (inclusive do próprio autor $)^{68}$ que mostram efetividade da injeção de células mononucleares da medula óssea sem o uso de prétratamento com GCSF ou MCSF (Macrophage colony stimulating factor).

Os autores afirmam que as CEP (fração $\mathrm{CD} 34^{+}$) produzem os múltiplos fatores angiogênicos (VEGF, FGF, angiopoietinas, fração $\mathrm{CD} 34$ ) e formam vasos novos estáveis, o que é confirmado pelos resultados aos seis meses e dispen- 
saria a administração adicional de VEGF e FGF e angiopoietinas. Esta seria, entretanto, uma linha de pesquisa desejável.

O autor termina: "Assim, o transplante autólogo de células mononucleares da medula óssea poderia constituir uma estratégia efetiva e segura para se conseguir a angiogênese terapêutica".

Yamamoto et al. ${ }^{33}$ demonstraram que as CEP circulantes estão diminuídas em pacientes com isquemia de membros e podem aumentar muito pelo implante de células mononucleares de medula óssea e de sangue periférico autógenas produzindo efeito angiogênico. Os autores estudaram três fontes de CEPs: medula óssea, sangue periférico após préestimulação com GCSF e cordão umbilical. A medula óssea foi a que apresentou o maior número de CEP e a que deu o melhor resultado clínico.

Kawamura et al. ${ }^{70}$ informaram a prevenção de amputação em pacientes em hemodiálise com úlceras isquêmicas, pelo implante de células mononucleares autógenas do sangue circulante. Conseguiram evitar a amputação em 21 de 30 pacientes com indicação.

O que chama a atenção neste estudo é que 24 pacientes eram diabéticos, mas 19 eram do tipo II. Apesar de serem casos muito graves, 21 pacientes evitaram a amputação em 22 membros com indicação. Foram injetadas, em média, 4,2×107 células $\mathrm{CD} 34^{+}$, em 65 pontos. A fonte foi o sangue periférico após pré-estimulação com GCSF.

Outros autores não confirmam resultados tão bons com células do sangue periférico, mesmo após estimulação com GCSF e expansão por cultura ex vivo. ${ }^{57,61}$

Outro ponto polêmico é a dose de GCSF usada: uns usam $350 \mathrm{mg} /$ dia nos quatro dias anteriores à coleta, ${ }^{71}$ outros usam $600 \mathrm{mg} /$ dia nos seis dias anteriores. ${ }^{72}$

Huang et al..$^{71}$ indicaram as células-tronco autógenas do sangue periférico como tratamento para isquemias graves de membros inferiores de origem aterosclerótica. Conseguiram evitar a amputação e obtiveram melhora da dor em todos os cinco pacientes que trataram. Também usaram GCSF como pré-estimulação e não notaram qualquer efeito adverso. Resultados considerados como definitivos já foram notados aos três meses.

Higashi et al. ${ }^{48}$ demonstraram que o implante de células mononucleares de medula óssea melhorava a vasodilatação dependente do endotélio em pacientes com isquemia de membros inferiores, isto é, melhorava a performance do endotélio dos vasos remanescentes.

Este trabalho é importante porque mostra que o transplante de células mononucleares da medula óssea, além de seu potencial angiogênico, tem capacidade de melhorar o desempenho do endotélio dos vasos em membros isquêmicos. Foram injetadas, em média, $1,6 \times 10^{9}$ células mononucleares, com cerca de $3,8 \times 10^{7}$ células $\mathrm{CD} 34^{+}$, em sete pacientes.

A resposta do fluxo foi avaliada antes e após o implante das células mediante a administração de acetilcolina (vaso- dilatador endotélio-dependente) e nitroprussiato de sódio (vasodilatador não dependente do endotélio). A resposta à acetilcolina (vasodilatador endotélio-dependente) foi muito maior após o implante das células, mas a resposta ao nitroprussiato não se alterava. Isto mostrava que as células da medula óssea sensibilizavam o endotélio à vasodilatação.

Yang et al. ${ }^{72}$ reportaram o uso, com bons resultados, de células-tronco do sangue periférico no tratamento de isquemia dos membros inferiores em 62 pacientes. Do total, 34 eram diabéticos; 54 pacientes (87\%) obtiveram melhora da dor isquêmica em repouso em sete a trinta dias e cura de úlceras de pés diabéticos em 16 casos.

Este artigo é escrito em chinês e tivemos acesso apenas ao resumo onde se nota:

- Usaram sangue periférico;

- A pré-estimulação com GCSF, também aqui, variou de 450 a $600 \mathrm{mg} /$ dia, durante cinco dias pré-coleta;

- O número de células mononucleares foi 0,718 $0,224 \times 10^{9}$

- O acompanhamento clínico-laboratorial deixa a desejar (fez angiografia em apenas cinco pacientes);

- Não detectaram nenhum efeito adverso local ou sistêmico, apesar de tratarem pacientes com etiologias diversas;

- Dezesseis, de quarenta pacientes (40\%) com úlceras isquêmicas, melhoraram;

- Dois pacientes que apresentavam infarto cerebral pioraram (seria a hipercoagulabilidade e granulocitose produzidos pelo GCSF?).

Enfim, é um trabalho para ser considerado com reservas, apesar do grande número de pacientes.

Ramirez et al. ${ }^{73}$ apresentaram um caso de transplante de células-tronco em paciente com isquemia crítica de membro inferior e lesão trófica, com excelente resultado após 24 semanas (desaparecimento da dor e cicatrização de áreas com necrose). Apenas um paciente, publicado em Cuba, muito parecido com os casos por nós tratados. Implantaram $1 \times 10^{9}$ células mononucleares com $3,4 \times 10^{7}$ células CD $34^{+}$e observaram melhora da dor já em 72 horas. A melhora de todos os parâmetros se manteve aos seis meses. Embora seja apenas um paciente, o resultado é altamente estimulante e se superpõe ao dos nossos quatro pacientes.

Nizankowski e colaboradores, na Polônia, apresentaram dez casos de implantes de células mononucleares autógenas de medula óssea em dez pacientes, dos quais sete puderam evitar amputações já indicadas. ${ }^{74}$

A metodologia é praticamente idêntica à de Yuyama, ${ }^{61}$ os resultados são excelentes (70\% evitaram amputações) e não houve qualquer efeito adverso. Curiosamente, sete pacientes tinham tromboangeíte obliterante e só três tinham arteriosclerose obliterante. Utilizaram noventa injeções de $0,5 \mathrm{ml}$. Em relação à doença arterial inflamatória, como tromboangeíte, Durdu S et al. ${ }^{75}$ relatam o tratamento de 28 pacientes com tromboangeíte obliterante (TAO) classe II e III de Rutherford 
com células mononucleares autógenas da medula óssea (CMMO) em pacientes sem sucesso ao tratamento clínico e a suspensão do tabaco com impossibilidade de revascularização cirúrgica. $\mathrm{O}$ trabalho mostra aumento do ITB $>0,15 \mathrm{em}$ oito pacientes aos três meses e em 14 pacientes aos seis meses. Observou a cicatrização total das úlceras isquêmicas em 15 pacientes (83\%) e melhora em três (17\%). Houve amputação de hálux em um paciente. Houve melhora da dor em repouso em todos os pacientes com suspensão dos analgésicos. Não relata complicações em 16,6 meses de média de acompanhamento. Apenas $40 \%$ suspenderam o tabaco após a terapia celular.

Já Takeshita ${ }^{76}$ relatou regressão total da dor isquêmica em pacientes com TAO em 36\% dos 11 membros tratados com a terapia celular (células mononucleares autógenas da medula óssea), com cicatrização completa em $88 \%$ (sete) dos 11 membros.

Este trabalho é importante, pois mostra efeitos adversos, a longo prazo, com a terapia celular em metade dos pacientes tratados, como a morte súbita, por causa não determinada, de um rapaz de 30 anos, após vinte meses de terapia celular. Um apresentou piora da úlcera com quatro meses e outro da dor em repouso com oito meses. Outro paciente desenvolveu uma fistula arteriovenosa no pé com sete meses, com regressão espontânea após um ano. O envolvimento das artérias coronárias na TAO é baixo, e o paciente que foi a óbito possuía a cintilografia miocárdica normal. Há estudos mostrando a possibilidade de participação de CMMO (células mononucleares da medula óssea) na aterogênese, como reporta Silvestre et al.,${ }^{77} \mathrm{em}$ seu artigo, que mostra aumento da placa aterosclerótica em ratos tratados com terapia celular. Como já foi dito, seria uma modulação inadequada das CTA. ${ }^{26}$

A formação de fístula arteriovenosa nos leva a pensar em possível processo de diferenciação e proliferação indesejada. Em relação à piora tardia da úlcera isquêmica, observou-se o mesmo padrão angiográfico desde o período de melhora da úlcera, sugerindo outros motivos para a piora.

Devemos questionar se os mecanismos de ação do transplante celular nas doenças inflamatórias são os mesmos da doença aterosclerótica. É por falta deste conhecimento que o autor deste trabalho sugeriu monitorização cuidadosa, a longo prazo, dos pacientes de doenças arteriais inflamatórias que, no futuro, receberão transplante de células mononucleares autógenas de medula óssea.

Nossa impressão é de que o sistema imunológico em doenças vasculares inflamatórias pode ter reação diferente da DAOP, com eventuais resultados adversos. Fazem-se necessárias, portanto, mais pesquisas e observação.

Além desses trabalhos citados, o Instituto Nacional de Saúde dos Estados Unidos ${ }^{78}$ tem 666 protocolos clínicos cadastrados em andamento, com uso de células-tronco para tratamento de doenças hematológicas, autoinumes, cardíacas, ósseas, inflamatórias, sistema venoso cerebral entre outros.
Com relação às doenças vasculares, há seis protocolos clínicos em fase I, com uso de CTMO: um em pacientes com claudicação intermitente incapacitante, quatro em isquemia crítica dos membros inferiores e outro no tratamento de vasculite com uso da imunoablação, com posterior transplante de células-tronco autógenas da medula óssea.

Vê-se, portanto, um grande interesse por esse tipo de terapia em patologias diversas de áreas diversas.

\section{Nossa experiência}

Em nossa Instituição, com autorização da Conep (Comissão Nacional de Ética em Pesquisa - Protocolo no 12277 , em 14/06/2006), realizamos o autotransplante de células-tronco da medula óssea em seis pacientes que apresentavam obstrução de todas as artérias dos membros em questão. Em todos os casos havia indicação de amputação menor ou maior e sem possibilidades de revascularização cirúrgica ou melhora somente com tratamento clínico.

Os critérios de inclusão para o protocolo são os seguintes:

- Pacientes com isquemia crítica, nos quais já se esgotaram todos os meios de tratamento conhecidos e aplicados com padrões de otimização. São pacientes que não têm nenhuma artéria permeável na perna para receber revascularização (sem run off). Se houver simultaneamente obstrução aortoilíaca, ela deve ser previamente tratada.

Os critérios para exclusão no protocolo são:

- Diabéticos insulino-dependentes de difícil compensação e já com retinopatia proliferativa.

- Pacientes com evidência de neoplasias nos últimos cinco anos.

- Pacientes com mais de 80 anos

Após análise destes critérios, os pacientes selecionados são submetidos a uma rigorosa análise clínica e laboratorial. São realizados:

- Avaliação vascular completa com determinação do Índice tornozelo/braço (ITB);

- Avaliação clínica (nefrológica, pneumológica e cardiológica);

- Avaliação oftalmológica;

- Pesquisa de marcadores tumorais para exclusão de possíveis neoplasias incipientes (CA 15-3, CEA, CA 125, CA 72-4, CA 19-9, alfafetoproteína, PSA, enolase, B-HcG, calcitonina, tireoglobulina);

- Inventário laboratorial completo;

- Estudo com dúplex scan das artérias dos membros inferiores com determinação da velocidade sistólica de pico e aferição do índice de velocidade de pico tornozelo/braço;

- Estudo angiográfico de aorta e artérias dos membros inferiores;

- Cintilografia de perfusão dos membros inferiores.

Estes pacientes, sem contra-indicações, são então encaminhados ao centro cirúrgico e submetidos à coleta 
de células-tronco da medula óssea através de punções na crista ilíaca póstero-superior, sob anestesia peridural com cateter.

Utilizamo-nos dos serviços do laboratório de terapia celular da Instituição, que participa do Estudo Multicêntrico de Terapia Celular em Cardiopatias do Ministério da Saúde, em três de seus quatro braços. A técnica de preparação das células mononucleares foi elaborada pela equipe de Terapia Celular, método de isolamento de células mononucleares, utilizando-se um meio de densidade (Ficoll).

Após o processamento, no mesmo dia, as células mononucleares são injetadas na musculatura da panturrilha dos membros isquêmicos através de uma grade demarcada com quarenta pontos equidistantes, nos quais é injetado $1 \mathrm{~mL}$ em cada ponto. $\mathrm{O}$ total de células mononucleares injetadas é de aproximadamente $3,6 \times 10^{8}$. (Figura 2 )

Realizamos acompanhamento diário de enzimas musculares - creatino fosfoquinase (CPK) - até o sétimo dia e curativos com adequada terapia antálgica. Em geral há uma elevação até o terceiro dia quando, então, regride rapidamente ao normal. (Figura 3 )

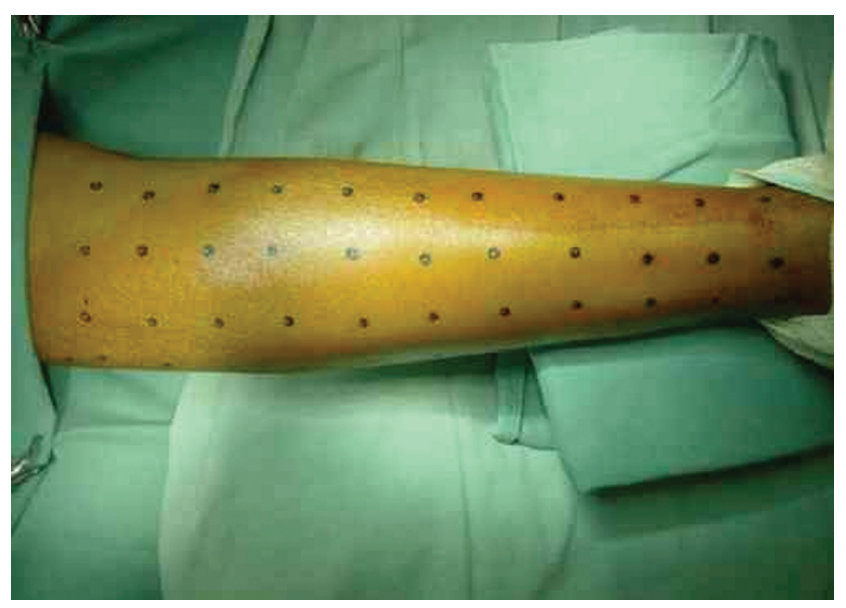

Figura 2

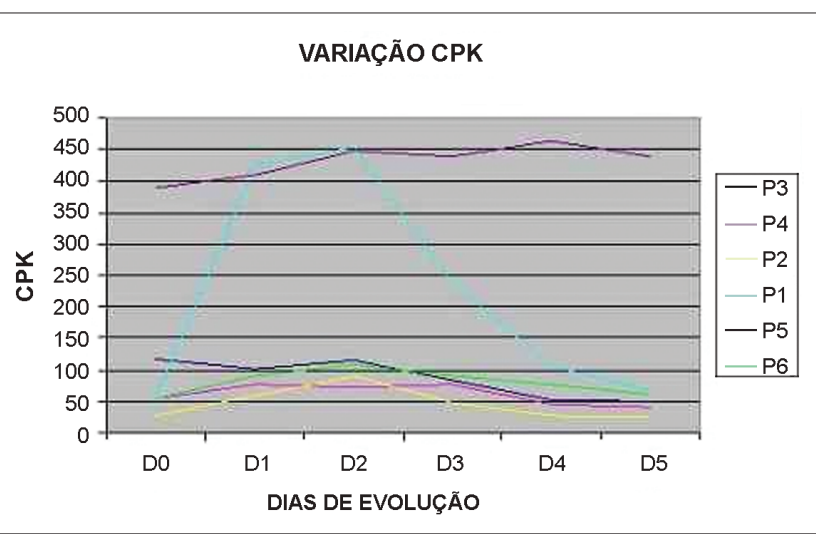

Figura 3

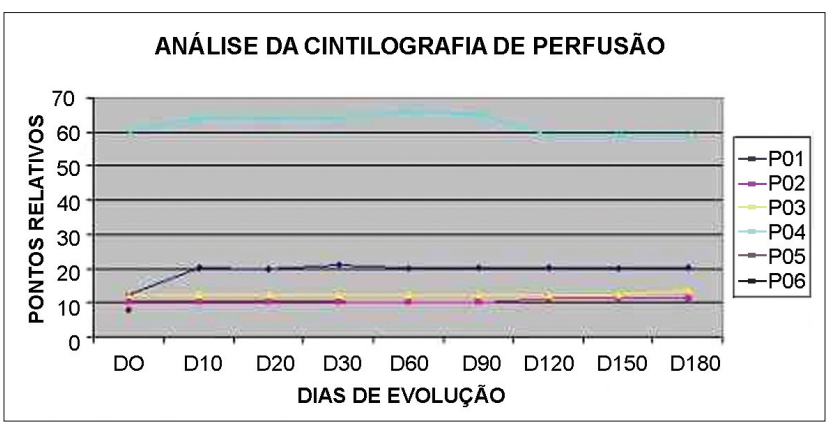

Figura 4

Realizamos, ainda, a comparação de perfusão muscular da perna antes e após os procedimentos, através de cintilografia de perfusão, e avaliamos a vascularização local através de arteriografias digitais pré e pós-procedimento. O princípio básico do estudo de perfusão com radioisótopos é a relação de proporcionalidade da sua concentração no tecido estudado com o fluxo sanguíneo regional. Utilizamos para a realização do estudo o traçador Sestamibi (2-metoxi-isobutilisonitrila), marcado com $20 \mathrm{mCi}$ do agente radioativo Tecnécio $99 \mathrm{~m}$. As imagens dos membros inferiores são adquiridas em câmara de cintilação Millenium MPR, com processamento das imagens em estação de trabalho Entegra. São adquiridas imagens de fluxo na projeção posterior dos membros inferiores e, posteriormente, imagens de equilíbrio tardias (até 20 minutos após a injeção), nas projeções anterior e posterior dos membros inferiores. Após a aquisição, são estabelecidas regiões a serem estudadas e, então, feitas as análises visual e quantitativa da captação do traçador nos membros inferiores bilateralmente. São realizados um estudo basal pré-procedimento e estudos seriados após os procedimentos. (Figura 4)

Para comprovar a permanência das células-tronco nos locais (tecidos) em que foram implantadas, realizamos a marcação celular em algumas amostras injetadas e acompanhamos com métodos cintilográficos sua possível migração. As células foram marcadas com Tecnécio 99 Tc 99 e HMPAO (I-hexamethylpropylene amine oxime). Este último apresenta tropismo para células neurais quando livres na corrente sanguínea. Entretanto, quando associamos o Tc99 ligado às células mononucleares injetadas, permaneciam gerando um foco importante de hipercaptação na musculatura da panturrilha, possivelmente devido à atração das citocinas liberadas no foco isquêmico. E isto se confirmava enquanto se mantinha a vida média do Tecnécio99 (aprox. 48 horas).

Simultaneamente, são determinados o índice tornozelo-braquial (ITB) e a velocidade sistólica de pico dos vasos da perna através do duplex scan, que é relacionado à velocidade na artéria umeral. Ocorre um aumento de temperatura local em todo o membro, com diminuição da dor logo nos primeiros dias, confirmado pela resposta à escala numérica 
de dor, reduzindo as necessidades de analgésicos potentes (Figura 5).

Os índices T/B e pico de velocidade sistólica mostram alterações já no quinto dia, com um aumento importante, que se mantém (Figuras 6 e 7).

Também observamos um aumento substancial na vascularização da perna e pé no $30^{\circ}$ dia, quando comparamos as arteriografias digitais pré e pós-procedimento, inclusive com visualização de artérias de maior calibre, que não eram visualizadas anteriormente (Figura 8).

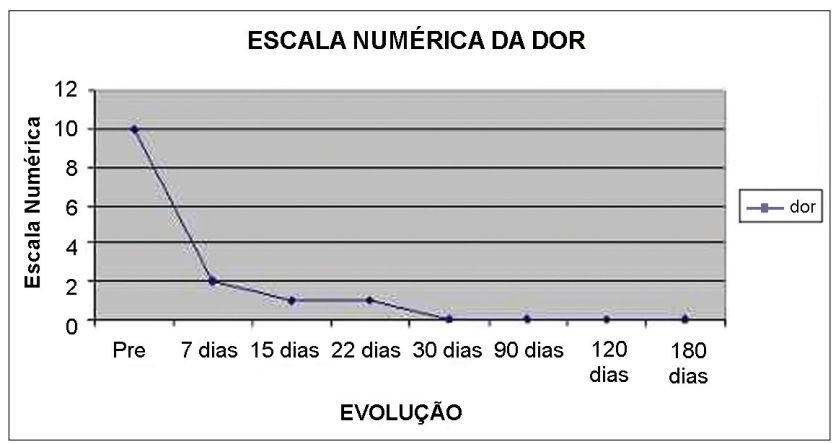

Figura 5

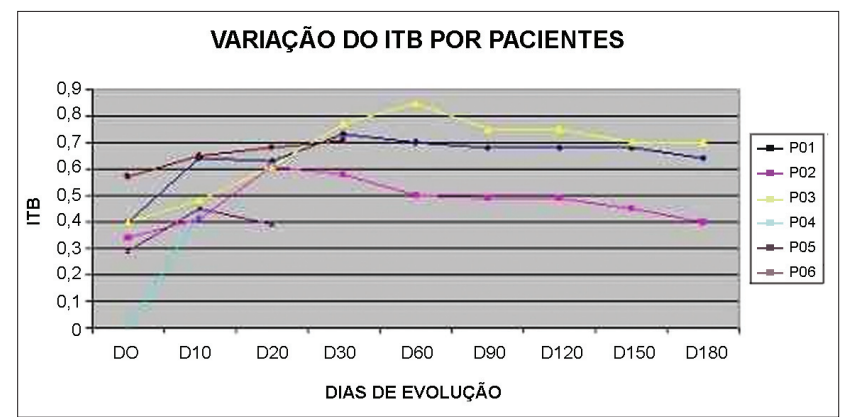

Figura 6

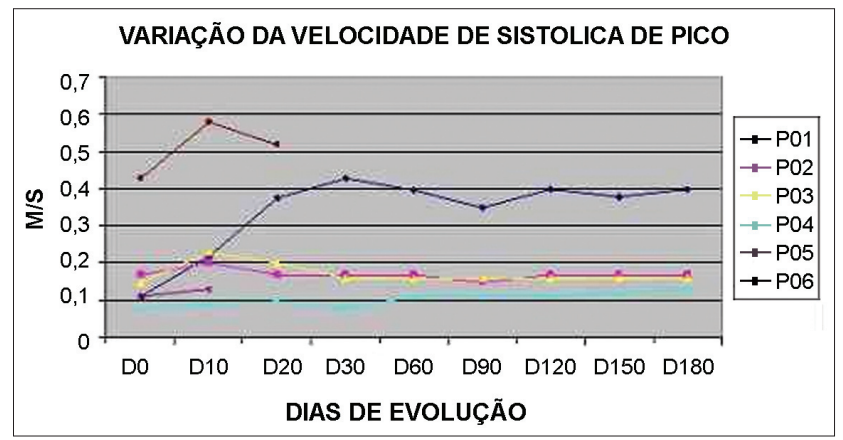

Figura 7

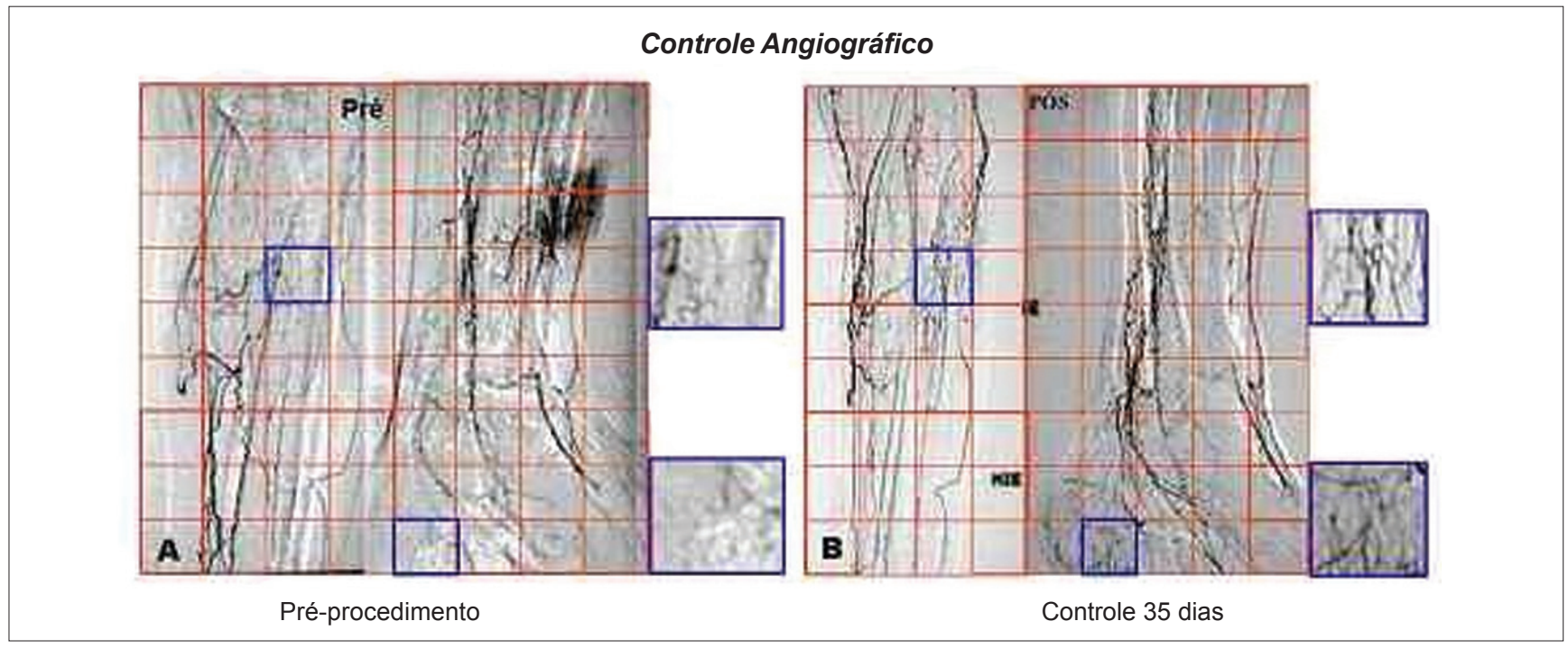

Figura 8
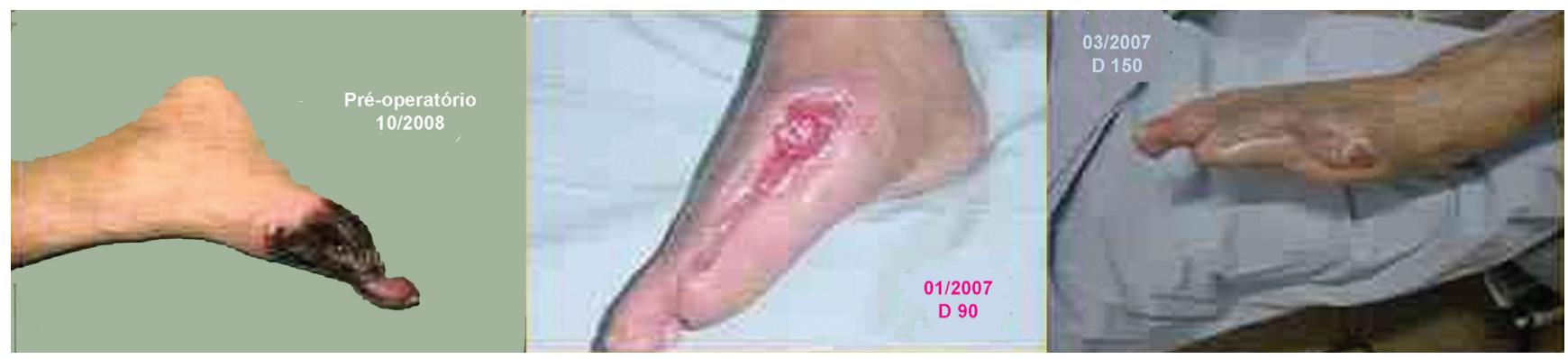

Figura 9 
Esses dados se mantêm, após 15 meses de seguimento, com cicatrização das lesões e supressão total da dor em repouso. Apenas em um paciente não conseguimos evitar amputação, mas conseguimos baixar o nível da amputação (perna), pois já apresentava necrose praticamente total do pé, previamente ao procedimento. Os demais cinco pacientes atualmente estão com as lesões completamente cicatrizadas e sem uso de analgésicos. (Figura 9)

Pelo que se conhece, até agora, a terapia celular representa, potencialmente, uma boa alternativa de tratamento para isquemia crítica dos membros inferiores. Obviamente, serão necessárias mais pesquisas e trabalhos randomizados e duplo-cegos para a consolidação deste conceito, que pode se tornar extremamente valioso para pacientes portadores desse tipo de patologia.

\section{Abstract \\ The authors discuss clinical aspects and conventional treatment of lower limb critical ischemia and the alternative of therapy with autogenous bone marrow stem cells in patients who have exhausted, without success, all the current means of treatment. They comment on the historical aspects, the sources, animal experiments, clinical research and, finally, their initial experience with six patients, all of whom had previous indication of major or minor amputation. For only one patient amputation could not be avoided. In addition to excellent results in pain relief and healing of ischemic ulcers, no deleterious side effects were noted suggesting that this type of cell therapy is safe and efficient although further research and randomized studies are needed to make this a standard therapy. Rev. Bras. Hematol. Hemoter. 2009;31(Supl. 1):128-139.}

Key words: Stem cell; critical ischemia; adult stem cells; bone marrow.

\section{Referências Bibliográficas}

1. Diehm C, Schuster A, Allenberg JR, Darius H, Haberl R, Lange S, et $a l$. High prevalence of peripheral arterial disease and co-morbidity in 6880 primary care patients: cross-sectional study. Atherosclerosis. 2004; 172(1):95-105

2. Newman AB, Siscovick DS, Manolio TA, Polak J, Fried LP, Borhani NO, et al. Ankle-arm index as a marker of atherosclerosis in the Cardiovascular Health Study. Cardiovascular Heart Study (CHS) Collaborative Research Group. Circulation. 1993;88 (3):83745.

3. Dormandy J, Heeck L, Vig S. The fate of patients with critical leg ischemia. Semin Vasc Surg. 1999;12(2):142-7.

4. Klinkert P, Post PN, Breslau PJ, van Bockel JH. Saphenous vein versus PTFE for above-knee femoropopliteal bypass. A review of the literature. Eur J Vasc Endovasc Surg. 2004;27(4):357-62.

5. Araújo JD. Técnicas cirúrgicas básicas na reconstrução vascular. In: Brito CJ. Cirurgia Vascular. Editora Revinter. 2002; v. I: 134-51.

6. Becquemin JP, Cavillon A, Allaire E, Haiduc F, Desgranges P. Iliac and femoropopliteal lesions: evaluation of balloon angioplasty and classical surgery. J Endovasc Surg. 1995; 2(1): 42-50.
7. de Godoy JM, de Godoy MF, Batigalia F, Trávolo AR, Monteiro EH. Lower-extremity amputation: a 6-year follow-up study in Brazil. J Orthop Surg (Hong Kong). 2005;13(2):164-6.

8. Tseng CH, Tai TY, Chong CK, Chen CJ, Lin BJ. Mortality in diabetic patients after lower extremity amputations. J Formos Med Assoc. 1994;93(10):842-8.

9. Fiessinger JN, Schäfer M. Trial of iloprost versus aspirin treatment for critical limb ischaemia of thromboangiitis obliterans. The TAO Study. Lancet. 1990;335(8689):555-7.

10. Second European Consensus Document on chronic critical leg ischemia. Circulation. 1991;84(4 Suppl):IV1-26.

11. Thomas ED, Lochte HL Jr, Cannon JH, Sahler OD, Ferrebee JW. Supralethal whole body irradiation and isologous marrow transplantation in man. J Clin Invest. 1959;38:1709-16.

12. Alison M, Sarraf C. Hepatic stem cells. J Hepatol. 1998; 29 (4): 676-82.

13. Gage FH. Mammalian neural stem cells. Science. 2000;287 (5457):1433-8.

14. Planat-Benard V, Silvestre JS, Cousin B, André M, Nibbelink M, Tamarat R, et al. Plasticity of human adipose lineage cells toward endothelial cells: physiological and therapeutic perspectives. Circulation. 2004;109(5):656-63.

15. Pittenger MF, Mackay AM, Beck SC, Jaiswal RK, Douglas R, Mosca JD, et al. Multilineage potential of adult human mesenchymal stem cells. Science. 1999;284(5411):143-7.

16. Shi Q, Rafii S, Wu MH, Wijelath ES, Yu C, Ishida A, et al. Evidence for circulating bone marrow-derived endothelial cells. Blood. 1998;92(2):362-7.

17. Reyes M, Lund T, Lenvik T, Aguiar D, Koodie L, Verfaillie CM. Purification and ex vivo expansion of postnatal human marrow mesodermal progenitor cells. Blood. 2001;98(9):2615-25.

18. Yoon YS, Wecker A, Heyd L, Park JS, Tkebuchava T, Kusano K, et al. Clonally expanded novel multipotent stem cells from human bone marrow regenerate myocardium after myocardial infarction. J Clin Invest. 2005;115(2):326-38.

19. Asahara T, Masuda H, Takahashi T, Kalka C, Pastore C, Silver M, et al. Bone marrow origin of endothelial progenitor cells responsible for postnatal vasculogenesis in physiological and pathological neovascularization. Circ Res. 1999;85(3):221-8.

20. Minamino T, Miyauchi H, Yoshida T, Ishida Y, Yoshida H, Komuro I. Endothelial cell senescence in human atherosclerosis: role of telomere in endothelial dysfunction. Circulation. 2002;105(13): 1541-4.

21. Rauscher FM, Goldschmidt-Clermont PJ, Davis BH, Wang T, Gregg $\mathrm{D}$, Ramaswami $\mathrm{P}$, et al. Aging, progenitor cell exhaustion, and atherosclerosis. Circulation. 2003;108(4):457-63.

22. Shimada T, Takeshita Y, Murohara T, Sasaki K, Egami K, Shintani $\mathrm{S}$, et al. Angiogenesis and vasculogenesis are impaired in the precocious-aging klotho mouse. Circulation. 2004;110(9): 1148-55.

23. Sata M. Circulating vascular progenitor cells contribute to vascular repair, remodeling, and lesion formation. Trends Cardiovasc Med. 2003;13(6):249-53

24. Gulati R, Jevremovic D, Peterson TE, Witt TA, Kleppe LS, Mueske $\mathrm{CS}$, et al. Autologous culture-modified mononuclear cells confer vascular protection after arterial injury. Circulation. 2003;108 (12): $1520-6$

25. Fujiyama S, Amano K, Uehira K, Yoshida M, Nishiwaki Y, Nozawa $\mathrm{Y}$, et al. Bone marrow monocyte lineage cells adhere on injured endothelium in a monocyte chemoattractant protein-1-dependent manner and accelerate reendothelialization as endothelial progenitor cells. Circ Res. 2003;93(10):980-9. 
26. Sata M, Saiura A, Kunisato A, Tojo A, Okada S, Tokuhisa T, et al. Hematopoietic stem cells differentiate into vascular cells that participate in the pathogenesis of atherosclerosis. Nat Med. 2002;8(4):403-9.

27. Boisvert WA, Spangenberg J, Curtiss LK. Treatment of severe hypercholesterolemia in apolipoprotein E-deficient mice by bone marrow transplantation. J Clin Invest. 1995;96(2):1118-24.

28. Rehman J, Li J, Parvathaneni L, Karlsson G, Panchal VR, Temm $\mathrm{CJ}$, et al. Exercise acutely increases circulating endothelial progenitor cells and monocyte-/macrophage-derived angiogenic cells. J Am Coll Cardiol. 2004;43(12):2314-8.

29. Dimmeler S, Aicher A, Vasa M, Mildner-Rihm C, Adler K, Tiemann $\mathrm{M}$, et al. $\mathrm{HMG}-\mathrm{CoA}$ reductase inhibitors (statins) increase endothelial progenitor cells via the PI 3-kinase/Akt pathway. J Clin Invest. 2001;108(3):391-7.

30. Vasa M, Fichtlscherer S, Adler K, Aicher A, Martin H, Zeiher AM. Increase in circulating endothelial progenitor cells by statin therapy in patients with stable coronary artery disease. Circulation. 2001; 103(24):2885-90.

31. Hill JM, Zalos G, Halcox JP, Schenke WH, Waclawiw MA, Quyyumi AA, et al. Circulating endothelial progenitor cells, vascular function, and cardiovascular risk. N Engl J Med. 2003; 348(7):593-600.

32. Waltenberger J, Lange J, Kranz A. Vascular endothelial growth factorA-induced chemotaxis of monocytes is attenuated in patients with diabetes mellitus: A potential predictor for the individual capacity to develop collaterals. Circulation. 2000; 102 (2):185-90.

33. Yamamoto K, Kondo T, Suzuki S, Izawa H, Kobayashi M, Emi N, et al. Molecular evaluation of endothelial progenitor cells in patients with ischemic limbs: therapeutic effect by stem cell transplantation. Arterioscler Thromb Vasc Biol. 2004;24(12):e192-6.

34. Ribatti D, Vacca A, Roncali L, Dammacco F. Hematopoiesis and angiogenesis: a link between two apparently independent processes. J Hematother Stem Cell Res. 2000;9(1):13-9.

35. Eichmann A, Corbel C, Nataf V, Vaigot P, Bréant C, Le Douarin NM. Ligand-dependent development of the endothelial and hemopoietic lineages from embryonic mesodermal cells expressing vascular endothelial growth factor receptor 2. Proc Natl Acad Sci USA. 1997;94(10):5141-6.

36. Shalaby F, Rossant J, Yamaguchi TP, Gertsenstein M, Wu XF, Breitman ML, et al. Failure of blood-island formation and vasculogenesis in Flk-1-deficient mice. Nature. 1995; 376 (6535): 62-6.

37. Shalaby F, Ho J, Stanford WL, Fischer KD, Schuh AC, Schwartz L, et al. A requirement for $\mathrm{Flk} 1$ in primitive and definitive hematopoiesis and vasculogenesis. Cell. 1997;89(6):981-90.

38. Nishikawa SI, Nishikawa S, Hirashima M, Matsuyoshi N, Kodama H. Progressive lineage analysis by cell sorting and culture identifies FLK1+VE-cadherin + cells at a diverging point of endothelial and hemopoietic lineages. Development. 1998;125 (9):1747-57.

39. Ribatti D, Vacca A, Nico B, Ria R, Dammacco F. Cross-talk between hematopoiesis and angiogenesis signaling pathways. Curr Mol Med. 2002;2(6):537-43.

40. Asahara T, Murohara T, Sullivan A, Silver M, van der Zee R, Li T, et al. Isolation of putative progenitor endothelial cells for angiogenesis. Science. 1997;275(5302):964-7.

41. Stump MM, Jordan GL Jr, Debakey ME, Halpert B. Endothelium grown from circulating blood on isolated intravascular Dacron hub. Am J Pathol. 1963;43:361-7.

42. Frazier OH, Baldwin RT, Eskin SG, Duncan JM. Immunochemical identification of human endothelial cells on the lining of a ventricular assist device. Tex Heart Inst J. 1993;20(2):78-82.
43. Carmeliet P. Mechanisms of angiogenesis and arteriogenesis. Nat Med. 2000;6(4):389-95.

44. Schaper W, Scholz D. Factors regulating arteriogenesis. Arterioscler Thromb Vasc Biol. 2003;23(7):1143-51.

45. Simons M. Angiogenesis: where do we stand now? Circulation. 2005;111(12):1556-66.

46. Iba O, Matsubara H, Nozawa Y, Fujiyama S, Amano K, Mori Y, et al. Angiogenesis by implantation of peripheral blood mononuclear cells and platelets into ischemic limbs. Circulation. 2002;106 (15):2019-25.

47. Rehman J, Li J, Orschell CM, March KL. Peripheral blood "endothelial progenitor cells" are derived from monocyte/ macrophages and secrete angiogenic growth factors. Circulation. 2003;107(8):1164-9.

48. Higashi Y, Kimura M, Hara K, Noma K, Jitsuiki D, Nakagawa K, et al. Autologous bone-marrow mononuclear cell implantation improves endothelium-dependent vasodilation in patients with limb ischemia. Circulation. 2004;109(10):1215-8.

49. You D, Waeckel L, Ebrahimian TG, Blanc-Brude O, Foubert P, Barateau $\mathrm{V}$, et al. Increase in vascular permeability and vasodilation are critical for proangiogenic effects of stem cell therapy. Circulation. 2006;114(4):328-38.

50. Dvorak HF. Vascular permeability factor/vascular endothelial growth factor: a critical cytokine in tumor angiogenesis and a potential target for diagnosis and therapy. J Clin Oncol. 2002; 20 (21):4368-80.

51. Smith RS Jr, Lin KF, Agata J, Chao L, Chao J. Human endothelial nitric oxide synthase gene delivery promotes angiogenesis in a rat model of hindlimb ischemia. Arterioscler Thromb Vasc Biol. 2002; 22(8): $1279-85$.

52. Tepper OM, Galiano RD, Capla JM, Kalka C, Gagne PJ, Jacobowitz GR, et al. Human endothelial progenitor cells from type II diabetics exhibit impaired proliferation, adhesion, and incorporation into vascular structures. Circulation. 2002;106(22):2781-6.

53. Ylä-Herttuala S, Alitalo K. Gene transfer as a tool to induce therapeutic vascular growth. Nat Med. 2003;9(6):694-701.

54. Comerota AJ, Throm RC, Miller KA, Henry T, Chronos N, Laird $\mathrm{J}$, et al. Naked plasmid DNA encoding fibroblast growth factor type 1 for the treatment of end-stage unreconstructible lower extremity ischemia: preliminary results of a phase I trial. J Vasc Surg. 2002;35(5):930-6.

55. Rafii S, Heissig B, Hattori K. Efficient mobilization and recruitment of marrow-derived endothelial and hematopoietic stem cells by adenoviral vectors expressing angiogenic factors. Gene Ther. 2002;9(10):631-41.

56. Asahara T, Bauters C, Zheng LP, Takeshita S, Bunting S, Ferrara N, et al. Synergistic effect of vascular endothelial growth factor and basic fibroblast growth factor on angiogenesis in vivo. Circulation. 1995;92(9 Suppl):II365-71.

57. Iwaguro H, Yamaguchi J, Kalka C, Murasawa S, Masuda H, Hayashi $\mathrm{S}$, et al. Endothelial progenitor cell vascular endothelial growth factor gene transfer for vascular regeneration. Circulation. 2002; 105(6):732-8.

58. Araújo JD, Araújo Filho Jd, Ciorlin E, Ruiz MA, Greco OT, Ardito $\mathrm{RV}$, et al. A terapia celular no tratamento da isquemia crítica dos membros inferiores. J Vasc Br 2005; 4(4): 357-65.

59. Peichev M, Naiyer AJ, Pereira D, Zhu Z, Lane WJ, Williams M, et al. Expression of VEGFR-2 and AC133 by circulating human CD34(+) cells identifies a population of functional endothelial precursors. Blood. 2000;95(3):952-8.

60. Rafii S. Circulating endothelial precursors: mystery, reality, and promise. J Clin Invest. 2000;105(1):17-9. 
61. Tateishi-Yuyama E, Matsubara H, Murohara T, Ikeda U, Shintani $\mathrm{S}$, Masaki $\mathrm{H}$, et al. Therapeutic angiogenesis for patients with limb ischaemia by autologous transplantation of bone-marrow cells: a pilot study and a randomised controlled trial. Lancet. 2002;360 (9331):427-35

62. Al-Khaldi A, A1-Sabti H, Galipeau J, Lachapelle K. Therapeutic angiogenesis using autologous bone marrow stromal cells: improved blood flow in a chronic limb ischemia model. Ann Thorac Surg. 2003;75(1):204-9.

63. Li TS, Hamano K, Suzuki K, Ito H, Zempo N, Matsuzaki M. Improved angiogenic potency by implantation of ex vivo hypoxia prestimulated bone marrow cells in rats. Am J Physiol Heart Circ Physiol. 2002;283(2):H468-73.

64. Kubo M, Li TS, Suzuki R, Ohshima M, Qin SL, Hamano K. Shortterm pretreatment with low-dose hydrogen peroxide enhances the efficacy of bone marrow cells for therapeutic angiogenesis. Am J Physiol Heart Circ Physiol. 2007;292(6):H2582-8.

65. Velazquez OC. Angiogenesis and vasculogenesis: inducing the growth of new blood vessels and wound healing by stimulation of bone marrow-derived progenitor cell mobilization and homing. J Vasc Surg. 2007;45 Suppl A:A39-47.

66. Thom SR, Fisher D, Zhang J, Bhopale VM, Ohnishi ST, Kotake Y, et al. Stimulation of perivascular nitric oxide synthesis by oxygen. Am J Physiol Heart Circ Physiol. 2003;284(4):H1230-9.

67. Golledge J, Van Campenhout A, Pal S, Rush C. Bone marrowderived cells and arterial disease. J Vasc Surg. 2007;46(3):590 600 .

68. Shintani S, Murohara T, Ikeda H, Ueno T, Sasaki K, Duan J, et al. Augmentation of postnatal neovascularization with autologous bone marrow transplantation. Circulation. 2001;103(6):897-903.

69. Silvestre JS, Mallat Z, Duriez M, Tamarat R, Bureau MF, Scherman D, et al. Antiangiogenic effect of interleukin-10 in ischemia-induced angiogenesis in mice hindlimb. Circ Res. 2000; $87(6): 448-52$

70. Kawamura A, Horie T, Tsuda I, Ikeda A, Egawa H, Imamura E, et al. Prevention of limb amputation in patients with limbs ulcers by autologous peripheral blood mononuclear cell implantation. Ther Apher Dial. 2005;9(1):59-63.

71. Huang PP, Li SZ, Han MZ, Xiao ZJ, Yang RC, Qiu LG. Autologous transplantation of peripheral blood stem cells as an effective therapeutic approach for severe arteriosclerosis obliterans of lower extremities. Thromb Haemost. 2004;91(3):606-9.
72. Yang XF, Wu YX, Wang HM, Xu YF, Lü X, Zhang YB, et al. Autologous peripheral blood stem cells transplantation in treatment of 62 cases of lower extremity ischemic disorder. Zhonghua Nei Ke Za Zhi. 2005;44(2):95-8.

73. Ramirez PH, Balea ED, Padron CH. Trasplante de celulas madre autólogas en el miembro inferior isquémico de un paciente con arteriosclerosis obliterante crítica. Rev Cubana Hematol Inmunol Hemoter 2005;21:33-38.

74. Nizankowski R, Petriczek T, Skotnicki A, Szczeklik A. The treatment of advanced chronic lower limb ischaemia with marrow stem cell autotransplantation. Kardiol Pol. 2005;63(4):351-60; discussion 361 .

75. Durdu S, Akar AR, Arat M, Sancak T, Eren NT, Ozyurda U. Autologous bone-marrow mononuclear cell implantation for patients with Rutherford grade II-III thromboangiitis obliterans. J Vasc Surg. 2006;44(4):732-9.

76. Miyamoto K, Nishigami K, Nagaya N, Akutsu K, Chiku M, Kamei $\mathrm{M}$, et al. Unblinded pilot study of autologous transplantation of bone marrow mononuclear cells in patients with thromboangiitis obliterans. Circulation. 2006;114(24):2679-84.

77. Silvestre JS, Gojova A, Brun V, Potteaux S, Esposito B, Duriez M, et al. Transplantation of bone marrow-derived mononuclear cells in ischemic apolipoprotein E-knockout mice accelerates atherosclerosis without altering plaque composition. Circulation. 2003;108(23):2839-42.

78. U.S. National Institutes of Health. (atualizada em dezembro de 2006, acesso em dezembro 2006). Disponível em: http://www. clinicaltrials.gov

Avaliação: O tema apresentado consta da pauta elaborada pelo editor, Professor Milton Artur Ruiz, e coeditores deste suplemento, Professores Sergio Paulo Bydlowski e Adriana Seber.

Conflito de interesse: não declarado

Recebido: $13 / 08 / 2008$

Aceito: 03/10/2008 